\title{
Activation of Terminal Components of Complement in Patients with Guillain-Barré Syndrome and Other Demyelinating Neuropathies
}

\author{
C. L. Koski, ${ }^{\star}$ M. E. Sanders, ${ }^{\ddagger}$ P. T. Swoveland, ${ }^{\star}$ T. J. Lawley, ${ }^{\ddagger}$ M. L. Shin, ${ }^{5}$ M. M. Frank, ${ }^{\ddagger}$ and K. A. Joiner ${ }^{\ddagger}$ \\ Departments of ${ }^{*}$ Neurology and ${ }^{\$}$ Pathology, University of Maryland School of Medicine, Baltimore, Maryland 21201; \\ and ${ }^{\ddagger}$ National Institutes of Allergy and Infectious Disease, National Institutes of Health, Bethesda, Maryland 20205
}

\section{Abstract}

In the present study, the role of antiperipheral nerve myelin antibody (anti-PNM Ab) in demyelination by generating the terminal attack complex (C5b-9) of complement was explored in patients with Guillain-Barré syndrome (GBS) and other demyelinating neuropathies. The presence in serum of SC5b-9, an inactive $\mathbf{C} 5 \mathrm{~b}-9$ containing $S$ protein, was assessed quantitatively by enzyme-linked immunosorbent assay using an antibody (Ab) to neoantigens expressed on $\mathrm{C} 9$ when complexed with C5b-8 or after tubular polymerization. SC5b-9 was detected in all $19 \mathrm{GBS}$, four patients with paraprotein-associated neuropathy and five of six patients with chronic recurrent polyneuritis. No SC5b-9 was detected in 10 normal controls. Kinetic studies from six GBS patients showed the highest values of SC5b-9 on the 3rd to 5th $d$ of admission; in contrast, the anti-PNM Ab were highest on the day of admission. AntiPNM Ab fell rapidly to very low levels by the 15th to 20 th $\mathrm{d}$. SC5b-9 declined with similar kinetics to undetectable levels by the 30th d. Levels of Ab and SC5b-9 did not quantitatively correlate with soluble immune complexes in these patients' serum. Membrane-bound C5b-9 was also detected by immunohistochemistry in the peripheral nerves from a GBS patient. These results, which show a relationship between levels of complement-fixing anti-PNM Ab and the tissue-damaging C5b-9 complex, suggest that peripheral nerve myelin may serve as the target for Ab-mediated complement attack.

\section{Introduction}

Diseases of peripheral nerve such as the Guillain-Barre syndrome (GBS), ${ }^{1}$ chronic recurrent polyneuritis (CRPN), and neuropathy associated with serum paraproteinemia are associated with inflammatory demyelination in which the myelin is believed to serve as the target of immune attack (1-4). Complement-fixing serum antibodies against antiperipheral nerve myelin antibody (anti-PNM Ab) have been detected in all three conditions (4-7). Furthermore, a putative role for

Address all correspondence to Dr. C. L. Koski, Department of Neurology, University of Maryland Hospital, 22 S. Greene St., Baltimore, MD 21201. 1987.

Received for publication 22 May 1986 and in revised form 1 April

1. Abbreviations used in this paper: $\mathrm{Ab}$, antibody; CRPN, chronic recurrent polyneuritis; GBS, Guillain-Barré syndrome; PBS/Tween, PBS containing 0.5\% Tween 20, pH 7.2; PNM, peripheral nerve myelin; VBS, barbital-buffered saline containing $145 \mathrm{mM} \mathrm{NaCl}, 5 \mathrm{mM}$ sodium barbital, $\mathrm{pH} 7.4$.

The Journal of Clinical Investigation, Inc.

Volume 80, November 1987, 1492-1497 antibody ( $\mathrm{Ab}$ ) in demyelination of peripheral nerve has been advanced since some patients with monoclonal gammopathy develop demyelination and the monoclonal immunoglobulin or paraprotein is directed against peripheral nerve myelin (PNM) (4). Serum from these patients as well as GBS patients can induce segmental demyelination after intraneural injection into cat or rat sciatic nerves (8-10). Even though declining serum titers of anti-PNM Ab correlate with clinical improvement during the monophasic illness of $\operatorname{GBS}$ patients $(7,11)$, it is unclear whether this $\mathrm{Ab}$ actively participates in myelin destruction by recruiting membrane attack systems such as complement or only reflects a host response to PNM antigens after myelin destruction.

Activation of the complement cascade through the classical or the alternative pathways, results in generation of inflammatory peptides as well as the terminal complement complexes C5b-8 or C5b-9, which form transmembrane channels when assembled in the lipid bilayer of a target membrane (see review 12 and 13). The C5b-9 that fails to assemble in the membrane forms a soluble, cytolyticaly inactive complex, SC5b-9, in the presence of S protein $(14,15)$. The presence of SC5b-9 therefore serves as an irrefutable marker for complement activation. Varying numbers of $\mathrm{C} 9$ can be incorporated into a single C5b-8 complex, which consists of one molecule each of $\mathrm{C} 5 \mathrm{~b}$, C6, C7, and C8 $(14,15)$. During this assembly, C9 undergoes conformational changes, thereby exposing neoantigenic determinants that are not present in the native molecule $(16,17)$. Using polyclonal or monoclonal $\mathrm{Ab}$ raised against $\mathrm{C} 9$ neoantigens, C5b-9 complexes have been detected in the involved tissues of glomerulonephritis (18), lupus dermatitis (19), dermatomyositis (20), and rheumatoid arthritis $(21,22)$. Recently we have also reported the presence of SC5b-9 in the cerebrospinal fluid of patients with GBS, multiple sclerosis, and other inflammatory central nervous system diseases such as systemic lupus erythrematosus (SLE) and syphilis (23).

The present study examined whether the anti-PNM Abs detected during the acute phase of illness in patients with demyelinating neuropathy participate in myelin destruction by recruitment of the terminal complement cascade. Specifically, we studied the quantity and kinetics of SC5b-9 in serum in relation to levels of complement-fixing anti-PNM Abs. Significant amounts of SC5b-9 were detected in patients with demyelinating neuropathy during acute illness and the kinetics of serum SC5b-9 in GBS patients showed a monophasic profile. The highest values of SC5b-9 occurred 3-5 d after admission in contrast to anti-PNM Ab that was highest on admission. Anti-PNM Ab and SC5b-9 declined with similar kinetics. Also, C5b-9 was detected in the peripheral nerves of a GBS patient by an immunohistochemical method. These results suggest that anti-PNM Ab activate complement, generating C5b-9 locally and in serum, possibly leading to complementmediated peripheral nerve demyelination. 


\section{Methods}

Collection of clinical material. Serum was collected from patients meeting criteria of the Ad Hoc Committee for GBS (24) during the acute phase of their illness, and stored at $-70^{\circ} \mathrm{C}$. Three or more serial serum samples were obtained during the course of GBS in six patients. Clinical presentations of these GBS patients included classic ascending paralysis with respiratory involvement, symmetrical multiple cranial neuropathy, or moderate proximal weakness. No GBS patient was treated with immunosuppressive drugs or plasmapheresis. Serum was also obtained from patients with peripheral neuropathy associated with serum paraproteinemia and patients with CRPN. Electrodiagnostic studies were performed to confirm clinical diagnosis. Serum was also obtained from patients with SLE, rheumatoid arthritis, cancer, paraproteinemia without neuropathy, poliomyelitis, sarcoidosis, alcoholism, diabetes, as well as other toxic and hereditary neuropathies. Control serum was from healthy laboratory workers.

Buffers. Veronal-buffered saline (VBS) at pH 7.4, $0.15 \mu \mathrm{m}$, was prepared by diluting a stock solution (25) fivefold with water. $\mathrm{GVB}^{++}$ was VBS with $0.1 \%$ gelatin, $0.15 \mathrm{mM} \mathrm{CaCl}_{2}$, and $1.0 \mathrm{mM} \mathrm{MgCl}_{2}$. EDTA/VBS was prepared by mixing $9 \mathrm{vol}$ of VBS with $1 \mathrm{vol}$ of $0.1 \mathrm{M}$ EDTA.

Complement and complement components. Guinea pig $\mathrm{C} 2$ was purchased from Cordis Laboratories Inc. (Miami, FL). Human serum congenitally deficient in C2, C2D-HS, was a gift of Dr. Jerry Winkelstein at The Johns Hopkins Medical School, Baltimore, MD, and of Dr. Henry Gerwurz at Rush Medical School, Chicago, IL. Fresh frozen guinea pig serum diluted 1:40 in EDTA/VBS was used as a source of $\mathrm{C} 3$ and $\mathrm{C5}-\mathrm{C}$.

$A b$. Rabbit IgG against human C9 neoantigen was prepared as described (26). In brief, the rabbits were immunized with polymerized, tubular $\mathrm{C} 9$ and the resulting antisera were extensively absorbed by passage first through a column of Sepharose 4B, bearing covalently linked human serum proteins, and then multiple times through a column of Sepharose 4B conjugated with normal human C9. The specificities of this anti- $\mathrm{C} 9$ neoantigen, demonstrating exclusive reactivity with SC5b-9, membrane-associated C5b-9, MC5b-9, and tubular poly $\mathrm{C} 9$, have been described previously $(23,26)$. Goat IgG to human C9 and alkaline phosphatase-conjugated swine anti-goat IgG were purchased from Miles Scientific Div., Miles Laboratories Inc. (Naperville, IL) and Tago Inc. (Burlingame, CA), respectively.

Determination of $S C 5 b-9$ in serum. The quantitative enzymelinked immunosorbent assay (ELISA) for serum SC5b-9 was performed on triplicate aliquots for each serum specimen. 96-well polystyrene plates (Dynatech Immulon II; Dynatech Laboratories, Inc., Dynatech Corp., Alexandria, VA) were coated overnight at $4^{\circ} \mathrm{C}$ with 100 $\mu \mathrm{l}$ of rabbit $\mathrm{IgG}$ to $\mathrm{C} 9$ neoantigen $(5 \mu \mathrm{g} / \mathrm{ml})$ in $0.5 \mathrm{M}$ sodium bicarbonate buffer, $\mathrm{pH}$ 9.6. The wells were washed with an automated ELISA plate washer, then incubated with $100 \mu \mathrm{l}$ of patient serum diluted 1:50 in phosphate-buffered saline (PBS) containing 0.5\% Tween $20, \mathrm{pH} 7.2$ (PBS/Tween) for $3 \mathrm{~h}$ at room temperature. The plates were washed again, and further incubated with $100 \mu$ l of goat anti-C9 IgG diluted 1:2,000 in PBS/Tween or PBS/Tween alone for $2 \mathrm{~h}$ at room temperature. The plates were washed and all wells were incubated with a 1:3,000 dilution of alkaline phosphatase-conjugated swine anti-goat IgG in PBS/Tween for $2 \mathrm{~h}$. After a final wash, $200 \mu \mathrm{l}$ of $p$-nitrophenylphosphate, $1 \mathrm{mg} / \mathrm{ml}$, in $10 \%$ diethanolamine buffer, $\mathrm{pH} 9.6$, were added to each well. The color of reaction was stopped at $1 \mathrm{~h}$ by the addition of $50 \mu \mathrm{l}$ 3-M sodium hydroxide, and quantitated in an automated ELISA reader at $405 \mathrm{~nm}$. (MR 580 Dynatech Micro ELISA Reader; Dynatech Laboratories Inc., Dynatech Corp.). To obtain a standard curve, SC5b-9 purified from zymosan-activated human serum as described in (26) was added to normal human serum diluted 1:50 in PBS/Tween. The standard curve was curvalinear between 0.1 to $20 \mu \mathrm{g} / \mathrm{ml}$ of SC5b-9. A control serum from a healthy individual was always run simultaneously. The SC $5 b-9$ values in the patient serum were determined by subtracting the mean optical density of each sample's background from the mean optical density of that same sample's experimental wells, then the concentrations were determined according to the standard curve. The assays were performed with coded samples.

Determination of Cl-fixing anti-PNM Abs in patients serum. The $\mathrm{Cl}$ fixation and transfer assay (27) were performed as described in detail previously $(7,11,28)$. Briefly, a fixed amount of PNM was incubated overnight with varying dilutions of human serum in a total $500-\mu l$ vol of $10 \mathrm{mM}$ EDTA in VBS at $4^{\circ} \mathrm{C}$. The myelin was washed three times with $1 \mathrm{ml} \mathrm{GVB}^{++}$by centrifugation in a microfuge (model B; Beckman Instruments, Inc., Fullerton, $\mathrm{CA}$ ) for $4 \mathrm{~min}$ at full speed. The myelin pellet was resuspended in $300 \mu$ lof C2D-HS (as a source of excess $\mathrm{Cl}$ ) diluted 500 -fold with $\mathrm{GVB}^{++}$, then incubated for $30 \mathrm{~min}$ at $37^{\circ} \mathrm{C}$. The myelin was washed three times with $1 \mathrm{ml}$ of $\mathrm{GVB}^{++}$per wash. The myelin slurry now carrying anti-PNM Abs, and $\mathrm{Cl}$ was incubated with sheep erythrocytes carrying anti-Forssman $\mathrm{Ab}, \mathrm{C} 4 \mathrm{~b}$ and $\mathrm{C} 3 \mathrm{~b}$, for 15 min at $30^{\circ} \mathrm{C}$. Incubations were further carried out first with excess guinea pig $\mathrm{C} 2$ then with EDTA-treated guinea pig serum as a source of C3, C5-C9. Lysis of cells was determined spectrophotometrically, and levels of anti-PNM Ab were calculated as described previously.

Determination of immune complexes in patients serum. The serum levels of soluble immune complexes in GBS patients were measured by the ${ }^{125}$ I-Clq-binding assay (29) to determine whether the SC5b-9 concentrations in serum could be correlated with the amount of immune complexes in these patients. Samples were run blindly in duplicates along with positive and normal human serum controls.

\section{Results}

Detection of $S C 5 b-9$ in patient serum. The presence of the SC5b-9 complex in serum of a variety of patients with demyelinating neuropathy was studied with a quantitative micro ELISA. Significant levels of SC5b-9 were detected in the serum of most patients with demyelinating neuropathy as shown in Fig. 1. The range of SC5b-9 in 19 GBS patients was 10-500 $\mu \mathrm{g} / \mathrm{ml}$, whereas that in four patients with paraprotein-associated neuropathy was $60-250 \mu \mathrm{g} / \mathrm{ml}$, and that in six of seven patients with CRPN was $5-500 \mu \mathrm{g} / \mathrm{ml}$. Serum SC5b-9 was also detected in five of twelve disease controls, namely, one patient with SLE $(225 \mu \mathrm{g} / \mathrm{ml})$, three patients with rheumatoid arthritis, $(25,60$, and $235 \mu \mathrm{g} / \mathrm{ml})$, and one patient with acute polio-

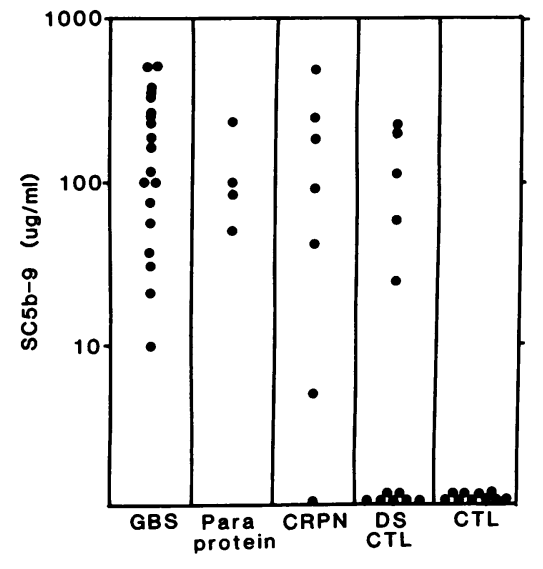

Figure 1. SC5b-9 in the serum of patients with demyelinating neuropathies. SC5b-9, detected in serum by a quantitative micro ELISA, is expressed in micrograms per milliliter on a $\log$ scale. Serum concentrations of SC5b-9 from 19 GBS patients, 4 patients with paraproteinemia and peripheral neuropathy, and 7 patients with CRPN are given, respectively, in columns from left to right. 12

patients with various diseases including axonal neuropathy, paraproteinemia without neuropathy, SLE, rheumatoid arthritis, and poliomyelitis (DS-CTL), and 10 healthy individuals (CTL) are shown in the two right columns. In the disease control group (DS-CTL), significantly elevated SC5b-9 levels were noted in a patient with SLE, in three patients with rheumatoid arthritis, and in one patient with acute poliomyelitis. 
myelitis $(110 \mu \mathrm{g} / \mathrm{ml})$. SC5b-9 was not detected in the serum of ten normal controls.

Kinetics of anti-PNM Ab, immune complexes, and SC5b-9 in the serum of $G B S$ patients. We next examined the relationship between serum levels of SC5b-9 and previously reported values of anti-PNM Ab (11) obtained from each of six GBS patients during their clinical disease course. $A b$ titers in this series varied from 0 to $256 \mathrm{U} / \mathrm{ml}$. Ab values in these kinetic studies are expressed as percent of the initial titer (35-256 $\mathrm{U} / \mathrm{ml}$ ) obtained on hospital admission (11). As shown in Fig. 2, anti-PNM Ab titers fell precipitously over the week and became either undetectable or very low 14-21 d after admission. The decline of $\mathrm{Ab}$ from the serum correlated with clinical improvement in muscular strength and pulmonary vital capacity as previously reported (11).

The results of SC5b-9 determination on the same serial serum samples are shown in Fig. 3. Absolute values ranged from 0 to $500 \mu \mathrm{g}$. For each patient SC5b-9 is expressed as a percent of the highest value for that patient, values of which ranged from 80 to $500 \mu \mathrm{g} / \mathrm{ml}$. Quantities of SC5b-9 rose rapidly and peaked around the 5th $\mathrm{d}$ after hospital admission. This rapid SC5b-9 production is followed by a slower rate of clearance to the undetectable level round the 30th $\mathrm{d}$. In one GBS patient SC5b-9 could be detected in a serum ( $\diamond$, Fig. 3 ) obtained 3 mo after the acute disease. Soluble immune complexes detected by the ${ }^{125} \mathrm{I}-\mathrm{Clq}$-binding assay (29) were expressed as follows; counts of ${ }^{125} \mathrm{I}-\mathrm{Clq}$ precipitated in EDTAtreated serum with $2.5 \%$ polyethyleneglycol were divided by the total ${ }^{125}$ I counts precipitated by TCA treatment of serum and multiplied by 100 . The upper $95 \%$ confidence limits in normal control serum was $10 \%$ as reported previously (29). The results in Table I showed the presence of immune complexes in only three of the six patients studied (patients 1, 2, and 5).

$C 5 b-9$ in peripheral nerve of a GBS patient. Finally, we examined peripheral nerve tissue for the presence of C5b-9 and $\mathrm{Ab}$. Sections of paraffin-embedded peripheral nerve and nerve roots obtained at autopsy of a GBS patient were stained with rabbit IgG to $C 9$ neoantigen, IgM ( $\mu$-chain specific), IgG ( $\gamma$-chain specific), and goat IgG to human C3. Binding was detected with a biotinylated goat anti-rabbit or rabbit anti-goat IgG and avidin-biotin reagent (30). Prominent and discrete staining by anti-C9 neoantigen was focal and segmental in nature (Fig. 4). Anti-IgM binding was found in the same areas of peripheral nerve stained with anti-C9 neoantigen and lim-

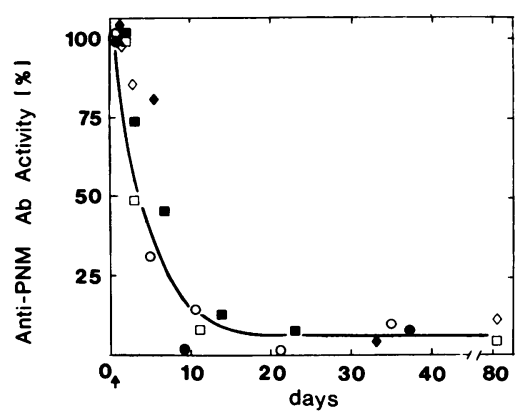

Figure 2. Kinetics of serum anti-PNM $\mathrm{Ab}$ in six GBS patients. AntiPNM Ab titers were measured on three or more samples obtained from each GBS patient (represented by a different symbol) during their clinical course. The titers are expressed as a percent of the initial titer obtained on admission (ordinate) which ranged between 35 to $256 \mathrm{U} / \mathrm{ml}$. AntiPNM Ab titers fell precipitously over 2 wk and became very low or undetectable by the 2 nd or 3 rd wk.

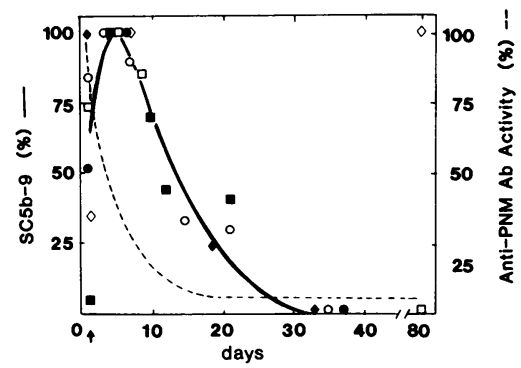

Figure 3. Kinetics of SC5b-9 in five GBS patients. SC5b-9 concentrations were determined on three or more serial samples obtained from each GBS patient. Symbols and samples in Fig. 3 are the same as those in Fig. 2. SC5b-9 is expressed as a percent of the highest value obtained for that patient, which ranged from $\mathbf{8 0}$ to $500 \mu \mathrm{g} / \mathrm{ml}$. Mean anti-PNM Ab levels for these patients are indicated by the broken line. Quantities of SC5b-9 rose rapidly and peaked around the $3 \mathrm{rd}$ to 5 th $\mathrm{d}$ after admission (ordinate), which was followed by a slower rate of decline to undetectable levels by the 30th d.

ited to segments of myelinated nerve fibers. Staining for C3 was much less intense than for $\mathrm{C} 9$ neoantigen, but was identifiable as a faint band on the surface of the myelin sheaths. No significant staining was observed in sections when nonimmune rabbit IgG or anti-human IgG was used in place of anti-C9 neoantigen. No immunostaining was found when nerves of normal controls obtained at autopsy were stained in a similar manner (results not shown).

\section{Discussion}

Using a quantitative micro ELISA, significant amounts of SC5b-9 were detected in the serum of patients with a variety of demyelinating neuropathies, including GBS, CRPN, and paraprotein-associated neuropathy. Significantly elevated quantities of SC5b-9 were also noted in disease controls with known immune complex formation such as SLE, rheumatoid arthritis, and poliomyelitis as reported previously by others $(21,31)$. Since C5b-9 can be generated only when there is activation of the terminal cascade of complement, the presence of SC5b-9 in body fluid can be used as a reliable evidence of terminal complement complex formation in vivo regardless of its mode of generation. In the present study, we used a multivalent anti-C9 neoantigen raised against tubular poly $\mathrm{C} 9$ to de-

Table I. Soluble Immune Complexes in GBS Serum

\begin{tabular}{|c|c|c|c|c|c|}
\hline \multirow[b]{2}{*}{ GBS } & \multicolumn{5}{|c|}{${ }^{125} \mathrm{I}-\mathrm{Clq}$ precipitated $(w k)^{*}$} \\
\hline & 1 & 2 & 3 & 4 & $5-12$ \\
\hline & $\%$ & $\%$ & $\%$ & $\%$ & $\%$ \\
\hline $1 \diamond^{\ddagger}$ & 29.1 & 27.6 & - & - & 9.0 \\
\hline 20 & $35, \$ 9.7^{\prime \prime}$ & 12.5 & 16.9 & 2.6 & - \\
\hline $3 \square$ & 2.4 & 2.1 & 2.6 & - & 3.1 \\
\hline $4 \bullet$ & 2.4 & 2.3 & - & 2.1 & - \\
\hline $5=$ & ND & 14 & ND & 7.3 & ND \\
\hline $6 \diamond$ & 4.6 & - & ND & - & ND \\
\hline
\end{tabular}

* $100 \%$ of protein-bound ${ }^{125}$ I precipitated as determined by $10 \%$ trichloroacetic precipitation; the upper 95\% confidence limit of Clqbinding assay in control population was $10 \%$.

${ }^{\ddagger}$ Each symbol corresponds to those used in Figs. 2 and 3.

${ }^{\S}$ Day 1 of hospital admission.

"Day 5. 


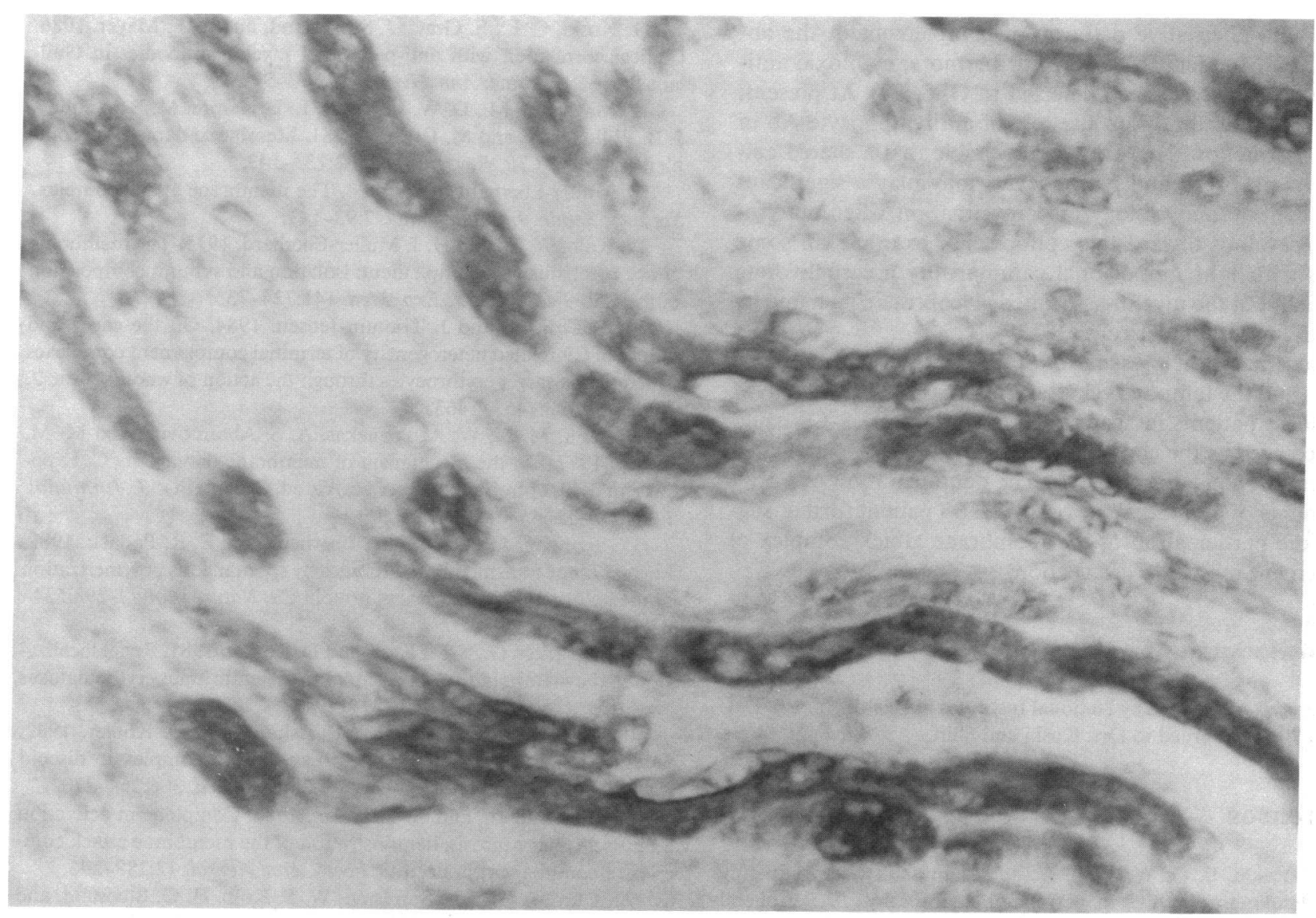

Figure 4. C9 neoantigen in the peripheral nerve of a GBS patient. Immunohistochemical staining of a parafin-embedded GBS nerve demonstrated the presence of $\mathrm{C} 9$ neoantigen in segments of myelinated nerve fibers. The deposits were focal and multiple involving spinal roots and peripheral nerves.

tect SC5b-9, based on the well known principle that $\mathrm{C} 9$ incorporated in C5b-8 also expresses neoantigenic determinants (32). Although anti-C9 neoantigen can also detect polymerized tubular C9 not associated with the C5b-8 complex (33), polymerization of tubular poly $\mathrm{C} 9$ in the absence of $\mathrm{C} 5 \mathrm{~b}-8$ is a slow and inefficient process, requiring prolonged incubation of purified $\mathrm{C} 9$ at higher concentrations than normally found in biologic systems (33). Thus, results obtained with anti-C9 neoantigen in our studies most likely reflect the $C 9$ neoantigen expressed on membrane-associated C5b-9 or in SC5b-9, the soluble cytolytically inactive form of the terminal complexes $(23,26)$. Low levels of SC5b-9 can form spontaneously during clot formation (34). However, this level of activation was included as background in all of our evaluations since normal human serum was used to dilute isolated SC5b-9 in our standard curve. With this method, no significant amount of SC5b-9 was observed in the serum of normal controls (Fig. 1).

The serum anti-PNM Abs during the acute phase in GBS patients are highest early in the course of disease when the patients are first seen $(7,11)$ (Fig. 2) and decline rapidly between 14 to $21 \mathrm{~d}$. The rapid clearance of anti-PNM Ab in these patients may be due to several factors such as the natural decay of serum IgM in a primary immune response (35) as well as the ongoing fixation of the Abs on peripheral myelin. These assumptions are based on observations that $\mathrm{Cl}$-fixing, anti-PNM $\mathrm{Ab}$ in acute-phase GBS have been identified as IgM isotypes in a few cases (7), and IgM was localized in the affected peripheral nerves of a GBS patient together with C5b-9 (Fig. 4) in the present study. During Ab clearance, SC5b-9 concentrations rapidly increased and reached their highest values at the 3rd-5th d after admission (Fig. 3). This cytolytically inactive complex subsequently cleared from circulation within $30 \mathrm{~d}$. The appearance of serum SC5b-9 in relation to anti-PNM Ab (Figs. 2 and 3) could reflect such ongoing fixation of serum $\mathrm{Ab}$ to myelin and subsequent generation of their activation product, SC5b-9. Immune complexes were not detected in three of six GBS patients (patients 3, 4, and 6, Table I) studied serially to determine SC5b-9 kinetics. Patients 1 and 2 (Table I) had strikingly elevated levels of soluble Cl-binding complexes early in the clinical course, but these did not uniformly correlate with significant SC5b-9 production. Serial SC5b-9 determinations in the first GBS patient listed in Table I showed the same rapid rise of SC5b-9 as did the other five patients shown in Fig. 3, but the SC5b-9 remained high in a serum obtained 3 mo after the onset of neurologic symptoms (Fig. 3) at a time when soluble immune complexes were not detectable. The presence of a coincident or contributing inflammatory disorder, if it existed as in some of our disease controls (Fig. 1), could explain such kinetics.

Mechanisms other than the fixation of anti-PNM Ab on PNM may also contribute to the generation of SC5b-9 observed in our studies since the $\mathrm{P}_{0}$ glycoprotein of human PNM 
activates the alternative pathway of complement in the absence of PNM-specific Ab (36). Furthermore, cytotoxic antilymphocyte Abs have been detected in GBS (37). At present, there is no information on the role of antilymphocyte $A b$ in myelin destruction. However, it is possible that a shared epitope between PNM and lymphocytes may play a significant role in the pathophysiology of demyelination when autoimmunity develops toward this epitope. For example, in some patients with IgM monoclonal gammapathy a carbohydrate determinant of the myelin-associated glycoprotein is shared by PNM and natural killer cells $(38,39)$.

In summary, the presence of SC5b-9 in the serum of GBS patients and the temporal relationship of SC5b-9 to anti-PNM $\mathrm{Ab}$ in these patients indicates that activation of $\mathrm{C} 5-\mathrm{C} 9$ could have occurred as the consequence of anti-PNM Ab-mediated complement activation in vivo. The demonstration of C5b-9 in segments of peripheral nerves of a GBS patient further suggested the participation of the membrane attack complex of complement in myelin destruction.

\section{Acknowledgments}

This work was supported by National Institutes of Health grants 1-P01 and NS-20022 awarded to Drs. Koski and Shin.

\section{References}

1. Arnason, B. G. W. 1984. Acute inflammatory demyelinating polyradiculoneuropathies in peripheral neuropathy. In Peripheral Neuropathy. P. J. Dyck, P. K. Thomas, E. H. Lambert, and R. Bunge, editors. W. B. Saunders Co., Philadelphia. 2050-2100.

2. Koski, C. L. 1984. Guillain Barre Syndrome. Neurol. Clin. 2:355-366.

3. Dyck, P. J., and B. G. W. Arnason. 1984. Chronic inflammatory demyelinating polyradiculoneuropathy. In Peripheral Neuropathy. P. J. Dyck, P. K. Thomas, E. H. Lambert, and R. Bunge, editors. W. B. Saunders Co., Philadelphia. 2101-2114.

4. Latov, N., W. H. Sherman, R. Nemni, G. Galassi, J. S. Shyong, A. S. Penn, L. Chess, M. R. Olarte, L. P. Rowland, and E. F. Osserman. 1980. Plasma cell dyscrasia and peripheral neuropathy with a monoclonal antibody to peripheral nerve myelin. N. Engl. J. Med. 303:618621.

5. Melnick, S. C. 1963. Thirty-eight cases of the Guillain-Barre' Syndrome: An immunological study. Br. Med. J. 1:368-373.

6. Latov, N., R. B. Gross, J. Kastelman, T. Flanagan, S. Lamme, D. A. Alkaitis, M. R. Olarte, W. H. Sherman, L. Chess, and A. S. Penn. 1981. Complement fixing antiperipheral nerve myelin antibodies in patients with inflammatory polyneuritis and with polyneuropathy and paraproteinemia. Neurology. 31:1530-1534.

7. Koski, C. L., R. Humphrey, and M. L. Shin. 1985. Anti-peripheral myelin antibody in patients with demyelinating neuropathy: quantitative and kinetic determination of serum antibody by complement component 1 fixation. Proc. Natl. Acad. Sci. USA. 82:905-909.

8. Feasby, T. E., A. F. Hahn, and J. J. Gilbert. 1982. Passive transfer of demyelinating activity in Guillain-Barre polyneuropathy. Neurology. 32:1159-1167.

9. Sumner, A. J., R. P. Lisak, M. J. Brown, and A. K. Asbury. 1983. Demyelinating activity of Guillain-Barre Syndrome (GBS) serum. Neurology. 33:81. (Abstr.)

10. Hays, A. P., M. Takatsu, N. Latov, and W. H. Sherman. 1983. Focal demyelination of cat sciatic nerve induced by intraneural injection of serum from patients with polyneuropathy and monoclonal IgM reactive with myelin-associated glycoprotein. J. Neuropath. \& Exp. Neurol. 42:349. (Abstr.)
11. Koski, C. L., E. Gratz, J. Sutherland, and R. F. Mayer. 1986. Clinical correlation with anti-peripheral myelin antibodies in Guillain-Barre Syndrome. Ann. Neurol. 19:573-577.

12. Mayer, M. M., D. W. Michaels, L. E. Ramm, M. B. Whitlow, J. B. Willoughby, and M. L. Shin. 1981. Membrane damage by complement CRC. Crit. Rev. Immunol. 2:133-143.

13. Muller-Eberhard, H. J. 1984. The membrane attack complex. Springer Semin. Immunopathol. 7:93-141.

14. Kolb, W. P., and H. J. Muller-Eberhard. 1975. The membrane attack mechanism of complement: isolation and subunit composition of the C5b-9 complex. J. Exp. Med. 141:724-735.

15. Bhakdi, S., and J. Tranum-Jensen. 1984. On the cause and nature of $\mathrm{C} 9$-related heterogeneity of terminal complement complexes generated on target erythrocytes through the action of whole serum. $J$. Immunol. 133:1453-1463.

16. Shin, M. L., W. A. Paznekas, A. S. Abramovitz, and M. M. Mayer. 1977. On the mechanism of membrane damage by C: Exposure of hydrophobic sites on activated C proteins. J. Immunol. 119:1358-1364.

17. Tschopp, J., H. J. Muller-Eberhard, and E. R. Podack. 1982. Formation of transmembrane tubules by spontaneous polymerization of the hydrophillic complement protein C9. Nature (Lond.). 298:534538.

18. Biesecker, G., S. M. Katz, and D. Koffler. 1981. Renal localization of the membrane attack complex in systemic lupus erythematosus nephritis. J. Exp. Med. 154:1779-1794.

19. Biesecker, G., L. Lavin, M. Ziskind, and D. Koffler. 1982. Cutaneous localization of the membrane attack complex in discoid and systemic lupus erythematosis. N. Engl. J. Med. 306:264-270.

20. Engel, A. G., and G. Biesecker. 1982. Complement activation in muscle fiber necrosis: demonstration of the membrane attack complex of complement in necrotic fibers. Ann. Neurol. 12:289-296.

21. Curd, J. G., J. S. Sundsmo, W. P. Kolb, H. G. Bluestein, and H. J. Muller-Eberhard. 1978. Neoantigen of the membrane attack complex of human complement occurrence on peripheral blood leukocytes from patients with systemic erythematosus. Arthritis Rheum. 21:177-182.

22. Sanders, M., J. Kopicky, F. Wigley, M. Shin, M. Frank, and K. Joiner. 1986. Membrane attack complex of complement in rheumatoid synovivial tissue demonstrated by immunofluorescent microscopy. J. Rheumatol. 13:1028-1034.

23. Sanders, M. E., C. L. Koski, D. Robbins, M. L. Shin, M. M. Frank, and K. A. Joiner. 1986. Activated terminal complement in cerebrospinal fluid in Guillain-Barre syndrome and multiple sclerosis. J. Immunol. 136:4456-4459.

24. Asbury, A., B. Arnason, H. Karp, and D. E. McFarlin. 1978. Criteria for the diagnosis of Guillain-Barre syndrome. Ann. Neurol. 3:565-566

25. Kabat, E. A., and M. M. Mayer. 1964. Complement and complement fixation. In Experimental Immunochemistry. Charles $\mathrm{C}$ Thomas, Publisher, Springfield, Illinois. 149-153.

26. Sanders, M. E., M. A. Schmetz, C. H. Hammer, M. M. Frank, and K. A. Joiner. 1985. Quantitation of activation of the human terminal complement pathway by ELISA. J. Immunol. Methods. 85:245256.

27. Borsos, T., and H. J. Rapp. 1965. Hemolysin titration based on fixation of the activated first component of complement: evidence that one molecule of hemolysin suffices to sensitize an erythrocyte. J. Immunol. 95:559-572.

28. Vanguri, P., C. L. Koski, B. Silverman, and M. L. Shin. 1982. Complement activation by isolated myelin: activation of the classical pathway in the absence of myelin-specific antibodies. Proc. Natl. Acad. Sci. USA. 79:3290-3294.

29. Lawley, T. J., H. M. Moutsopoulos, S. I. Katz, A. N. Theofilopoulos, T. M. Chused, and M. M. Frank. 1979. Demonstration of circulating immune complexes in Sjogrens syndrome. J. Immunol. 123:1382-1387.

30. Hsu, S., L. Raine, and H. Fanger. 1981. Use of avidin-biotin 
peroxidase complex $(\mathrm{ABC})$ in immunoperoxidase techniques: a comparison between $\mathrm{ABC}$ and unlabelled antibody (PAP) procedures. $J$. Histochem. Cytochem. 29:577-580.

31. Falk, R. J., A. P. Dalmasso, Y. Kim, S. Lam, and A. F. Michael 1984. Radioimmunoassay of the attack complex of complement in sera from patients with glomerulonephritis. Clin. Res. 32:503. (Abstr.)

32. Podack, E. R., J. Tschopp, and H. J. Muller-Eberhard. 1982. Molecular organization of $\mathrm{C} 9$ within the membrane attack complex of complement. J. Exp. Med. 156:268-282.

33. Falk, R. J., A. P. Dalmasso, Y. Kim, C. H. Tsai, J. I. Scheiman, H. Gewurz, and A. F. Michael. 1983. Neoantigen of the polymerized ninth component of complement. J. Clin. Invest. 72:560-573.

34. Mollnes, T. E., T. Lea, S. S. Froland, and M. Harboe. 1985. Quantification of the terminal complement complex in human plasma by an enzyme linked immunosorbent assay based on monoclonal antibodies against a neoantigen of the complex. Scand. J. Immunol. 22:197-202.
35. Golub, E. S. 1981. Proliferation and maturation. In The Cellular Basis of the Immune Response. Sinauer Associates, Inc., Sunderland, Massachusetts. 237-249.

36. Koski, C. L., P. Vanguri, and M. L. Shin. 1985. Activation of the alternative pathway of complement by human peripheral nerve myelin. J. Immunol. 134:1810-1814.

37. Searles, R. P., L. E. Davies, S. Hermanson, and C. J. Froelich. 1981. Lymphocytotoxic antibodies in Guillain Barre Syndrome. Lancet. i:273-275.

38. McGarry, R. C., S. C. Helfand, R. H. Quarles, and J. C. Roder. 1983. Recognition of myelin associated glycoprotein by the monoclonal antibody HNK-1. Nature (Lond.). 306:376-379.

39. Nobile-Orazio, E., A. P. Hays, N. Latov, G. Pernan, J. Golier, M. E. Shy, and L. Freddo. 1984. Specificity of mouse and human monoclonal antibodies to myelin-associated glycoprotein. Neurology. $34: 1336-1342$. 